\title{
EDUCAÇÃO DE JOVENS E ADULTOS EM CONTEXTO DE PRIVAÇÃO DE LIBERDADE: ANÁLISE DE NARRATIVAS DE UM SUJEITO-EDUCANDO
}

\author{
CLEIA PANTOJA ANDRADE \\ Universidade Federal do Amapá \\ - ALDER DE SOUSA DIAS \\ Universidade Federal do Amapá \\ - ELIANE LEAL VASQUEZ \\ Universidade Federal do Amapá \\ WALDIR FERREIRA ABREU \\ Universidade Federal do Pará
}

RESUMO O artigo analisa narrativas de um sujeito-educando da modalidade Educação de Jovens e Adultos (EJA) de uma escola prisional. Resulta de uma pesquisa qualitativa do tipo (auto)biográfica. Aponta-se a carência afetiva familiar, relações desumanas na educação e o convívio com duas lógicas opostas dentro do cárcere: a da escola e a dos operadores do sistema penitenciário. Sobre a vida pós-cárcere, o sujeito-educando vislumbra reconstruir sua vida e vê na educação escolar um dos meios para esse fim. Conclui-se afirmando que a educação em espaço de privação de liberdade deve considerar a materialidade dos seus sujeitos-educandos nos princípios educacionais e nas estratégias metodológicas, tendo em vista a humanização. Palavras-chave: EJA. Privação de liberdade. Narrativas. Sujeito-educando. Perfil. Vida pós-cárcere.

\section{ABSTRACT YOUTH AND ADULT EDUCATION IN CONTEXT OF LIBERTY DEPRIVATION: ANALYSIS OF NARRATIVES OF A LEARNER SUBJECT}

The article analyzes narratives of a learner subject of the modality of Youth and Adult Education (YAE) from a prison school. This work results from qualitative research of the autobiographical type. It points the lack of family affection, inhuman relations in education, and the 
coexistence with two opposite types of logic within the prison: the one of the school, and the penitentiary system operators. Regarding post-prison life, the learner subject envisions rebuilding his life and sees in school education one of the means to that end. The education in the space of deprivation of liberty must consider the materiality of its learner subjects in the educational principles and methodological strategies, with a view towards humanization.

Keywords: YAE. Deprivation of liberty. Narrative. Learner subject. Profile. Post-prison life.

\section{RESUMEN EDUCACIÓN DE JÓVENES Y ADULTOS EN CONTEXTO DE PRIVACIÓN DE LIBERTAD: ANÁLISIS DE NARRATIVAS DE UN SUJETO-EDUCANDO}

El artículo analiza narrativas de un sujeto-educando de la modalidad Educación de Jóvenes y Adultos (EJA) de una escuela prisional. Es resultado de una investigación cualitativa del tipo (auto)biográfica. Se apunta la carencia afectiva familiar, relaciones inhumanas en la educación y la convivencia con dos lógicas opuestas dentro de la cárcel: la de la escuela y la de los operadores del sistema penitenciario. Sobre la vida post-cárcel, el sujeto-educando vislumbra reconstruir su vida y ve en la educación escolar uno de los medios para ese fin. Se concluye afirmando que la educación en contexto de privación de libertad debe considerar la materialidad de sus sujetos-educandos en los principios educativos y en las estrategias metodológicas, con miras a la humanización.

Palabras clave: EJA. Privación de libertad. Narrativas. Sujeto-educando. Perfil. Vida posterior a la prisión.

\section{Introdução}

A educação escolar que ocorre no interior de prisões está ligada à Educação de Jovens e Adultos (EJA), modalidade de ensino orientada a sujeitos-educandos, oriundos da classe trabalhadora e de grupos sociais economicamente desfavorecidos, que não iniciaram ou não concluíram a educação básica escolar por diversos motivos.

Neste sentido, é válido pontuar as singularidades da EJA, no contexto prisional, visto que a promoção de um ensino de qualidade, para além de ensinar os conhecimentos historica- mente produzidos pela humanidade, requer, primordialmente, que a instituição escolar conheça a realidade de seus sujeitos-educandos, para assim estabelecer uma relação entre os saberes escolares e os saberes cotidianos, como destaca Freire (2002, p. 33):

Por isso mesmo pensar certo coloca ao professor ou, mais amplamente, à escola, o dever de não só respeitar os saberes com que os educandos, sobretudo os das classes populares, chegam a ela - saberes socialmente construídos na prática comunitária - mas também, como há mais 
de trinta anos venho sugerindo, discutir com os alunos a razão de ser de alguns desses saberes em relação com o ensino dos conteúdos.

Conhecer tais singularidades e a historicidade dos sujeitos-educandos que vivem sob privação de liberdade foi o principal motivador para realizar a pesquisa da qual resulta este artigo, pois um de seus autores atua como professora da Educação de Jovens e Adultos (EJA), em espaço de privação de liberdade, desde 2009, quando foi designada pela Secretaria de Educação do Estado do Amapá (SEED/AP), para trabalhar na Escola Estadual São José, localizada no Instituto de Administração Penitenciária do Estado do Amapá (IAPEN).

Considera-se também que a EJA, modalidade eleita pelos órgãos que gerenciam a educação nacional como a mais apropriada para ser ofertada às pessoas que estão privadas de liberdade, é timidamente discutida nos cursos de formação de professores.

Desde 2005, os Ministérios da Educação (MEC) e da Justiça (MJ), em parceria com a representação da Organização das Nações Unidas para a Educação, a Ciência e a Cultura (UNESCO) no Brasil, deram o passo inicial com o projeto "Educando para a Liberdade", discutindo políticas públicas que possam assegurar os direitos constitucionais aos sujeitos privados de liberdade, entre os quais o direito à educação, cujo objetivo, conforme a UNESCO (2006, p. 14), é: “Promover uma educação que contribua para a reintegração posterior do indivíduo à sociedade, bem como para a finalidade básica da educação nacional: realização pessoal, exercício da cidadania e preparação para o trabalho".

Este passo inicial ganhou força com a Resolução no 02 , de maio de 2010, expedida pelo MEC, que dispõe sobre as Diretrizes Nacionais para a Oferta da Educação de Jovens e Adultos em Situação de Privação de Liberdade. No artigo 5으, observa a colaboração das esferas estaduais e federais que deverão incentivar a promoção de novas estratégias pedagógicas, atendendo também às especificidades da educação prisional.

Art.5o. Os estados, o Distrito Federal e a União, levando em consideração as especificidades da educação em espaços de privação de liberdade, deverão incentivar a promoção de novas estratégias pedagógicas, produção de materiais didáticos e a implementação de novas metodologias e tecnologias educacionais, assim como de programas educativos na Modalidade à Distância (EAD), a serem empregados no âmbito das escolas do sistema prisional. (BRASIL, 2010, p. 335)

Sobre a promoção de estratégias que atendam as especificidades da educação em espaços de privação de liberdade é que se direciona o objetivo geral deste artigo, que se propõe a analisar narrativas de um sujeito-educando privado de liberdade, com foco em aspectos sociais, culturais, educacionais e a perspectiva pós-cárcere. Assim, adotam-se os seguintes objetivos específicos: (1) identificar o perfil sociocultural do sujeito-educando da EJA; e (2) explicitar o perfil socioeducacional do referido sujeito-educando.

Espera-se que este estudo contribua não só para ampliar as discussões sobre a EJA, no contexto da privação de liberdade, como também com uma educação de jovens e adultos comprometida com a melhoria das condições de vida de seus sujeitos-educandos.

\section{Caminho metodológico}

Este artigo resulta de uma pesquisa de abordagem (auto)biográfica, de matriz sociológica, pois tem foco "[...] sobre os aspectos da vida

de uma pessoa ou grupo de pessoas, relativo a uma prática social" (BRAGANÇA; MAURícIO, 2008 , p. 261, grifo nosso). Neste caso, o foco está nos aspectos socioculturais, socioeducacionais e nas projeções do existir no contexto pós-cárcere. 
O locus da pesquisa é a Escola Estadual São José, localizada no interior do Instituto de Administração Penitenciário do Estado do Amapá (IAPEN). Considerando que em termos metodológicos a pesquisa (auto)biográfica pode ser realizada com uma pessoa, optou-se por se eleger como sujeito da pesquisa uma pessoa privada de liberdade, há 16 anos, do sexo masculino, 35 anos de idade, amasiado, e pai de quatro filhos. Para efeito de preservação da identidade do sujeito da pesquisa, e tendo em vista o cumprimento de critérios éticos, este será identificado neste artigo como R. TRINDADE. O mesmo assinou o Termo de Consentimento Livre e Esclarecido, conforme modelo da Resolução no. 466/2012-CNS/ CONEP.

Ao se adotar a compreensão de DeloryMomberger (2008, p. 97) sobre o papel da narrativa para a vida do sujeito - "A narrativa realiza sobre o material indefinido da experiência vivida um trabalho de homogeneização, ordenação e funcionalidade significante: ela reúne, organiza, tematiza os acontecimentos da existência, dá sentido a um sentido multiforme, heterogêneo e polissêmico" - utiliza-se, como técnica de coleta de dados, a entrevista narrativa: "[...] durante a qual um 'pesquisador' (que pode ser um estudante) pede a uma pessoa, então denominada 'sujeito', que the conte toda ou uma parte de sua experiência vivida" (BERTAUX, 2010, p. 15). Foram realizadas 24 sessões de entrevista narrativa, com base em um roteiro semiestruturado, com ênfase no narrar e não na pergunta, e o auxílio de gravador de voz.

Os dados das entrevistas foram transcritos, realocados em quadros analíticos elaborados em editor de texto e organizados nas seguintes categorias temáticas: dados dos sujeitos-educandos; perfil sociocultural; perfil socioeducacional e vida pós-cárcere. Ressalta-se que as categorias temáticas são um meio de organi- zação de dados próprio da análise de conteúdo (BARDIN, 2011).

\section{EJA em contexto de privação de liberdade: desafios e contribuições}

De acordo com o pensamento foucaultiano, a prisão preexiste a sua utilização sistemática nas leis penais, mas foi instituída legalmente como pena de privação de liberdade, no final do século XVIII e início do século XIX, em cidades da Europa e Estados Unidos. (FOUCAULT, 2012).

Apresentada como a nova forma do poder de punir, a prisão surge para humanizar a justiça penal e substituir gradualmente as penas físicas, como o suplício, por exemplo, que "consistia na pena corporal dolorosa realizada através de uma cerimônia punitiva e aterrorizante, pela qual mostrava-se não somente a superioridade da Lei, mas também o poder do soberano sobre o infrator" (FOUCAULT, 2012, p. 35).

Já instituído, esse novo modelo de punição é adaptado, em outras nações como o Brasil, que passa a utilizá-lo em conjunto com a disciplina, a vigilância, a ordem, bem como outras técnicas penitenciárias, entre elas a educação penitenciária.

Vasquez (2008), ao analisar os regulamentos que normatizavam as instituições penais no Brasil, aborda que a instrução escolar é permeada de concepções de educação que vão se modificando ao longo do tempo. No Brasil Império, época em que se observa a entrada desta instrução, a concepção de educação que se tinha, a princípio, era moral e religiosa, ficando sob a responsabilidade do capelão, segundo a autora; os regulamentos ainda apontam para uma preocupação com a concepção intelectual, que tinha como objetivo ensinar a leitura, a escrita e as operações matemáticas, estas sob a responsabilidade da professora de primeiras letras. 
Na década de 1900, com a ampliação do programa curricular que compreenderia "[...] leitura, escrita, arithimética elementar, noções rudimentares de gramática, noções de geografia principalmente do Brasil, noções de história pátria, e noções dos direitos e deveres morais e políticos" (VASQUEZ, 2008, p. 79), a educação, que passa a ser intelectual, ficava agora sob a responsabilidade do professor.

Em 1957, ainda de acordo com Vasquez (2008), as Normas Gerais do Regime Penitenciário, disciplinadas pela Lei 3274 de 02 de outubro do referido ano, apresentavam de forma implícita uma concepção de educação integral, visto que o currículo também passou a abranger a educação física, a educação artística e a educação profissional.

Durante o governo militar, período em se observa a entrada da instrução escolar no âmbito do sistema penitenciário amapaense, a autora elenca a instituição do Código Penal no 1004 de 1969 e da Lei de Execução Penal no 7.210 de 1984, que vigora atualmente, e nesta, a prescrição da obrigatoriedade da educação em nivel fundamental, com formação escolar, profissional e religiosa. Quanto à entrada da instrução escolar, no sistema penitenciário amapaense, ao preso condenado e provisório, a autora destaca sua divisão em três fases:

1a fase (1975-1995) em radioposto e teleposto localizados na Colônia Penal de São Pedro, Penitenciária agrícola ou Colônia Penal Agrícola e industrial do Amapá; 2a fase (1996-2004), na escola anexa do Centro de Estudos Supletivos Emílio Médice localizada no Complexo Penitenciário, o qual a partir de 2011 passou a denominar-se Instituto de Administração penitenciária do Amapá e 3á fase (2004- a atual), na Escola Estadual São José, localizada no Instituto de Administração Penitenciária do Amapá. (VASQUEZ, 2008, p. 99)

A primeira fase foi desenvolvida com a implantação do Programa de Educação Integrada e do Projeto Minerva, concepção de educação da época. A segunda fase foi marcada pelo ensino personalizado ofertado por módulo de disciplina, na 3a e 4a etapas do Ensino Fundamental, bem como os cursos de suplência, em nível de alfabetização de 1a e 2a etapas da EJA. Já a terceira fase é marcada pela implantação de turmas regulares desta modalidade de ensino e, a partir de 2006, a oferta do Ensino Médio.

De acordo com o breve histórico sobre a entrada da educação escolar nas prisões brasileiras, bem como da EJA, é oportuno dizer que ambas as concepções pedagógicas de ensino são semelhantes, principalmente no que se refere ao caráter político, pois funcionavam como reforço ideológico do Estado, para modificar os comportamentos dos indivíduos. Diferenciam-se, quanto ao público alvo, já que envolvem a população carcerária e a população de jovens e adultos.

Faz-se necessário dizer também que, com o processo de redemocratização do país, a concepção pedagógica da educação básica foi modificada e considerada como um direito de todos, a instrução escolar foi dando ênfase ao preparo para a cidadania. Além desse enfoque, a educação, no âmbito prisional, foi considerada como parte dos tratamentos penitenciários, enfocando também a reintegração do indivíduo recluso à sociedade brasileira.

Essa lógica da educação escolar, e o seu acesso dentro das prisões, já vinha sendo discutida e contemplada nos normativos internacionais, como as Regras Mínimas para o Tratamento de Reclusos, adotadas em 1955 pelo Primeiro Congresso das Nações Unidas Sobre a Prevenção do Crime e Tratamento do Delinquente. A regra 77 desse normativo prevê:

1) Devem ser tomadas medidas no sentido de melhorar a educação de todos os reclusos que daí tirem proveito, incluindo instrução religiosa nos países em que tal for possivel. A educação de analfabetos e jovens 
reclusos será obrigatória, prestando-lhe a administração especial atenção.

2) Tanto quanto for possivel, a educação dos reclusos deve estar integrada no sistema educacional do país, para que depois da sua libertação possam continuar, sem dificuldades, a sua educação. (UNESCO, 1955, p. 18)

Cabe ressaltar que este marco internacional, que instituiu a educação em estabelecimentos penitenciários, está embasado legalmente na Declaração Universal dos Direitos Humanos de 1948 (ONU, 1948), e no Pacto Internacional de Direitos Econômicos, Sociais e Culturais de 1966, que compreendem a educação como um direito de todos, nos seus respectivos artigos 26 e 13 (BRASIL, 1992).

Ainda em âmbito internacional, a V Conferência Internacional de Educação de Adultos (CONFITEA), realizada em Hamburgo, na Alemanha, em 1997, aprova o Plano de Ação para o Futuro, cuja meta 47 faz referência específica à população carcerária, reconhecendo seu direito à aprendizagem, informando-a sobre as oportunidades de ensino e de formação, em diversos níveis, bem como a permissão para o acesso à mesma.

No Brasil, a educação em contexto prisional vem sendo disciplinada pelas Diretrizes Nacionais para a Oferta de Educação de Jovens e Adultos em Situação de Privação de Liberdade nos Estabelecimentos Penais, homologada pelo Ministério da Educação (MEC), por meio da Resolução no 2 do CNE, em 19 de maio de 2010 (BRASIL, 2010).

No Estado do Amapá, esta educação está amparada pela Resolução no 57 de 2015, do Conselho Estadual de Educação (CEE/AP) que, no seu artigo 10, estabelece as normas reguladoras para a oferta da educação básica e superior nas modalidades de Educação de Jovens e Adultos, Educação Profissional e Tecnológica e Educação a Distância para jovens e adultos privados de liberdade, extensivos aos presos provisórios condenados, egressos do sistema prisional e aqueles que cumprem medida de segurança (AMAPÁ, 2015).

Além desses normativos, a Lei de Execução Penal no 7.210 de 1984, já citada anteriormente, aborda, em seu artigo 17, que a assistência educacional destinada ao preso compreenderá a instrução escolar e a formação profissional (BRASIL, 1984). E desde 29 de junho de 2011 passou a ser determinado, no artigo 126 da referida lei, a remissão de pena pelos estudos, pois antes se remia somente pelo trabalho.

Observa-se que a atual Lei de diretrizes e Bases da Educação Nacional (BRASIL, 1996) omite o direito à educação à população carcerária até mesmo nos dispositivos destinados à EJA, mesmo sendo elaborada e instituída muito depois da Lei de Execução Penal. Esse direito, porém, foi contemplado na meta 17 do Plano Nacional de Educação de 2001 (BRASIL, 2001), que estabelece que os Programas de Educação de Jovens e Adultos de nível fundamental, médio e profissional deverão ser implantados em todas as unidades prisionais.

Assim como a Educação de Jovens e Adultos nas escolas públicas enfrenta seus desafios, em contexto de privação de liberdade não é diferente. Embora haja obstáculos à implementação de políticas educacionais destinadas aos jovens e adultos privados de liberdade, percebe-se um avanço na legislação, ainda que haja também um hiato tanto naquilo que ela determina quanto em sua aplicabilidade, conforme se explicita nos parágrafos a seguir.

0 artigo 70 das Diretrizes Nacionais para a Oferta de Educação de Jovens e Adultos em Situação de Privação de Liberdade nos Estabelecimentos Penais (BRASIL, 2010), por exemplo, recomenda espaços físicos adequados às atividades educacionais, esportivas, culturais, profissionais e de lazer. Cabe ressaltar, que a Escola São José opera suas atividades em um espaço pequeno, dispondo de apenas quatro 
salas de aula, para comportar, de acordo com os dados da secretaria da Escola Estadual São José, as 375 vagas ofertadas na penitenciária masculina, o que mostra ser insignificante, se levamos em consideração, ainda, o número da população carcerária, estimada em 2716 internos, conforme os dados da Coordenadoria de Execução Penal do IAPEN.

A referida legislação, também prescreve a implementação de materiais didáticos, novas metodologias e tecnologias educacionais, bem como a formação continuada para educadores, gestores e técnicos, entre outros.

Quanto à formação continuada, os professores esperam por um curso de especialização específico no campo da educação em contexto de privação de liberdade.

A solução para tais problemas depende da aprovação do Plano Estadual de Educação Para o Sistema Penitenciário Amapaense, que deverá captar recursos financeiros junto ao MEC e ao $\mathrm{MJ}$, principalmente para a infraestrutura da escola, o que garantirá a ampliação da matrícula na educação escolar, prevista na meta I do referido plano. 0 Plano Estadual de Educação Para o Sistema Penitenciário Amapaense (AMAPÁ, 2017), também estabelece na meta VI, a melhoria na qualidade da oferta de educação para os anos de 2017, 2018 e 2019, preconizando, para isso, a formação de professores, a distribuição de material pedagógico e didático, bem como equipar e aparelhar os espaços destinados às atividades educacionais.

Os estudos de Onofre (2007), também destacam os obstáculos que esta educação enfrenta para se efetivar em contexto de privação de liberdade. Entretanto, também expressam sua relevância por contribuírem não só no processo de humanização, mas também na conscientização e formação do aprisionado.

Nesse sentido, esta autora elenca que embora não seja a única responsável por isso, a oferta da educação no ambiente prisional é considerada "[...] como ferramenta adequada para o processo formativo, pois é capaz de produzir mudanças de atitude contribuindo assim para um processo de integração social" (ONOFRE, 2007, p. 8).

Scarfó (2003 apud ONOFRE, 2011, p. 278) entende que o papel dessa educação, para além da informação, consiste em três objetivos imediatos:

[...] manter o aluno envolvido em atividades de maneira proveitosa, melhorar sua qualidade de vida e criar condições para que a experiência educativa the traga resultados úteis (trabalho, conhecimento, compreensão, atitudes sociais e comportamentos desejáveis que perdurem e lhe permitam acesso ao mercado de trabalho e continuidade nos estudos). Essa educação poderá reduzir a reincidência, reintegrando-o eficazmente à sociedade.

Em seus apontamentos, Abreu (2008, p. 21) argumenta que "a educação nas prisões não deve ser concebida como mera medida humanitária ou estratégia de gestão prisional, e sim um direito do preso à cidadania". o que torna pertinente afirmar que a Educação Prisional estando ligada à EJA, além de contribuir para a reintegração social de seus sujeitos-educandos, possui também uma função reparadora, visto que ameniza a desigualdade e os estigmas sociais dos que foram agenciados para 0 mundo do crime, resgatando sua cidadania.

\section{Concepção de sujeitos- educandos}

Dias (2017) explicita elementos para uma concepção dos sujeitos-educandos da Educação de Jovens e Adultos com foco na valorização da vida humana, buscando se orientar por uma pedagogia pautada na humanização e na libertação, que rompe laços com a pedagogia tradicional.

O autor opta pela nomenclatura "sujeitos -educandos", em detrimento dos termos "alu- 
no" e "educando". Segundo ele, o termo aluno é uma identificação formal, típica da pedagogia tradicional:

[...] do Latim, a-lunos, sendo que o prefixo a indica a noção de ausência e lunos, deriva de lux, que se refere à luz. A grosso modo, o termo 'aluno' estabelece e mantém uma ideia de que, individualmente, o 'sujeito-educando' se constitui em um ente 'sem-luz', o que em termos ontológicos, 'castra' a existência humana, sobretudo no que se refere à possibilidade de produzir cultura, história e conhecimento. (DIAS, 2017, p. 260)

Já o termo "educando", segundo o autor, ainda que apresente o significado filosófico -educacional de aprender permanentemente, reforça somente os processos gnosiológicos e não os antropológicos, como a culturalidade, a historicidade e a sociabilidade.

Com base na teoria da educação popular freireana, Dias (2017) salienta que a compreensão do termo "sujeitos-educandos" está para além dos processos gnosiológicos centrados na escola, enquanto instituição. Reconhece o estar sendo dos educandos no e com o mundo, que se inicia muito antes da educação escolar. Dessa forma, reconhece-se, em primeiro plano, o ser sujeito dos educandos envolvidos no processo educativo, pois são pessoas que possuem uma experiência de vida em uma determinada sociedade, em vários círculos sociais, familiares e profissionais.

Os sujeitos-educandos da Educação de Jovens e Adultos então apresentam uma heterogeneidade com relação à idade, especificidades sociais, culturais, políticas e educacionais. Assim, segundo Oliveira (1999), eles possuem marcas identitárias inerentes:

0 adulto, no âmbito da educação de jovens e adultos, não é o estudante universitário, o profissional qualificado que frequenta cursos de formação [...]. Ele é geralmente migrante que chega às grandes metrópoles proveniente de áreas rurais empobrecidas, filho de trabalhado- res rurais não qualificados e com baixo nível de instrução escolar (muito frequentemente analfabetos), ele próprio com uma passagem curta e não sistemática pela escola e trabalhando em ocupações urbanas não qualificadas, após experiência no trabalho rural na infância e na adolescência, que busca a escola tardiamente para alfabetizar-se ou cursar algumas séries do ensino supletivo. (OLIVEIRA, 1999, p. 59)

Ao se posicionar sobre a caracterização dos sujeitos-educandos da EJA, Arroyo (2011, p. 24) argumenta que, além de identificar estas especificidades, “[...] é preciso enxergar esses sujeitos como protagonistas também em suas trajetórias humanas". Nesse sentido, é de fundamental importância que a escola identifique, reconheça a realidade dos seus sujeitos -educandos, pois é uma forma de fazer com que os conhecimentos escolares dialoguem com ela. Em relação aos sujeitos-educandos em contexto de privação de liberdade, é preciso levar em consideração a cultura da prisão e os efeitos do encarceramento.

Goffman (1974, p. 24) destaca que "a imagem que o indivíduo tem de si e de toda sua cultura adquirida no convívio social, são atacadas quando ele adentra à prisão". Começa então uma série de rebaixamentos, degradações e profanações do "eu", devido aos processos pelos quais passa. Primeiramente, ele é despojado de sua vida civil, visto que há imposições de barreiras para o contato com o mundo externo. Em seguida, ele passa pelo enquadramento das normas, que irão regular sua vida no cárcere. Passa também pelo despojamento dos bens (roupas, material de higiene) e essa privação contribui para a perda da identidade.

Foucault (2012) observa que dentro da prisão se manifesta um poder arbitrário, por parte dos dirigentes, o que faz com que o apenado deixe de ser réu e passe a se enxergar como uma vítima, e, nesse sentido, o sentimento de injustiça que começa a cultivar é um dos fatores que podem tornar seu caráter indomável. 
É preciso saber também que, além do poder institucional, os grupos de detentos também convivem com o poder prisional, que, de acordo com Vasquez (2008), são as normas e regras determinadas pelos presos mais antigos.

Dentro do cárcere, as pessoas custodiadas também buscam se reorganizar com táticas de adaptação com as quais adquirem novas atitudes e comportamentos que irão garantir sua sobrevivência. Eles passam a conviver com a cultura prisional, como aponta Clemer (1960, p. 148 apud VASQUEZ, 2008, p. 123-124): "As pessoas que ficam submetidas ao confinamento dentro das prisões vivenciam o fenômeno da prisonização que corresponde à adoção em maior ou menor grau do modo de pensar, hábitos, costumes e cultura geral da penitenciária".

Ao falar do contexto da prisão, Maeyer (2006, p. 44) também ressalta que o que menos se aprende dentro das prisões não são os programas ou currículos pensados por especialistas em educação, pois por apresentar a prisão um contexto que imobiliza e desconstrói o ser, só terá valor de aprendizagem ao interno aquilo que irá saciar suas necessidades e urgências, sejam elas de sobreviver ou simplesmente para existir dentro cárcere.

Os sujeitos-educandos da EJA em contexto de privação de liberdade, além de absorverem a cultura prisional e sofrerem os efeitos do encarceramento, também convivem com o descrédito dos operadores do sistema penitenciário em relação ao direito à educação, pois a educação escolar é vista como um privilégio. Conforme os estudos de Viana (2015), muitos sujeitos-educandos da Escola São José apontam principalmente os agentes penitenciários como obstáculo que os impede de frequentar regulamente as aulas, pois consideram a escola como um lugar onde o reeducando quer passar o tempo.
Assim, compreende-se que o contexto prisional apresenta dilemas, mostrando ser um ambiente contraditório à educação escolar. Entretanto, estas devem se comprometer com a pedagogia da humanização e libertação, levando em consideração a materialidade dos seus sujeitos-educandos, ressaltando não só suas positividades, mas também suas negatividades e reconhecendo-os como protagonistas do processo ensino-aprendizagem.

\section{Análise sobre narrativas}

\section{socioeducacionais de um sujeito- educando privado de liberdade: \\ o perfil sociocultural}

Evidenciar o perfil do sujeito-educando da EJA por meio de fatores sociais e culturais faz-se relevante porque, como afirmam Gadotti e Romão (2011), a EJA integra processos educativos desenvolvidos em múltiplas dimensões que vão além do letramento. Trata-se aqui, portanto, de (re)conhecer, identificar e valorizar a identidade do sujeito-educando, tendo como base os questionamentos sobre seus aspectos sociais e culturais.

Nesses termos, constata-se que R. Trindade é proveniente da zona rural, que pouco frequentou a escola quando criança e adolescente, e que seus responsáveis legais (no caso, pai, mãe e posteriormente padrasto) eram analfabetos e exerciam, respectivamente, a profissão de caseiro, doméstica e pedreiro.

Nessas narrativas, evidencia-se em Oliveira (1999), ao caracterizar as marcas identitárias do sujeito que frequenta a EJA, que, em geral, são: migrantes de áreas rurais empobrecidas, têm rápida passagem pela escola e são filhos de trabalhadores rurais com baixa escolaridade quando não analfabetos.

Contudo, deve-se atentar para a ressalva de Dias (2017), que aponta para a necessidade 
de se construírem dados mais objetivos sobre o perfil dos sujeitos-educandos da EJA, em diferentes conjunturas, ou seja, deve-se ter um olhar para além da caracterização geral, com o fim de gerar perfis socioculturais e socioeducacionais que considerem as especificidades destes sujeitos. Assim, têm-se subsídios para uma compreensão mais aprofundada da concepção de sujeito-educando, o que pode contribuir para processos educativos e políticos mais humanizados e que respeitem a materialidade destes sujeitos.

Nesse sentido, os relatos de R. Trindade apontam para uma especificidade não está no rol de caracterização de Oliveira (1999): a carência afetiva familiar motivada pela separação dos pais e a entrada do padrasto na família, o que contribuiu para sua passagem curta e não sistemática pela escola, na infância e adolescência e foi o motivo pelo qual fugiu de sua casa, conforme indica o trecho da narrativa a seguir:

Morava no Paredão com minha família e com oito anos de idade nós viemos de cá pra Macapá. Lembro que chegando aqui meu pai adoeceu e minha mãe veio ter outro relacionamento com outra pessoa. Aí minha vida começou a ficar conturbada, não era uma convivência legal porque eu e a minha irmã não éramos filhos dele, tudo que a gente fazia era motivo para gente apanhar [...] e isso foi trazendo uma revolta muito grande no meu coração.

Percebe-se que a memória afetiva de $\mathrm{R}$. Trindade se refere ao convívio com a mãe, a irmã e o pai biológico, que segundo ele era muito presente: provedor do lar, não deixava faltar nada. Realidade que mudou com a chegada do padrasto, do qual fala com mágoa.

[...] ele proibiu de eu ir no velório do meu pai [...] até a minha adolescência foi assim conturbada [...] ele só saía com os três filhos que ele teve com a minha mãe, as coisas melhores eram pra eles [...] eu tinha brinquedo porque uma vizinha me dava [...] eu ajudava no sustento da casa.
Ainda nesse aspecto sociocultural, procurou-se atentar também para interpretar por quais motivos os responsáveis de R. Trindade foram declarados por ele analfabetos. Conforme já visto, legalmente, a educação é um direito social e cabe também à família assegurá-lo. Porém, observa-se que tal direito não foi também garantido aos responsáveis do sujeito da pesquisa, o que os coloca como vítimas de um sistema educacional que historicamente tem suas raízes fincadas na segregação, na discriminação, no elitismo e no autoritarismo, como evidenciado em Freire (1995). Dessa forma, as narrativas apontam para relações desumanas na educação, tanto para a família quanto para o narrador.

\section{O perfil socioeducacional de um sujeito-educando privado de liberdade}

Conhecer a trajetória escolar do narrador antes e depois do seu encarceramento é importante, na medida em que se evidenciam fatores a contribuir para a sua marginalização social e da vida escolar, assim como oferece meios para se compreender a concepção de educação que se quer para as pessoas jovens e adultas.

Como explicitado anteriormente, as narrativas apontam que as relações da escola com $R$. Trindade mostraram-se desumanas, visto que, enquanto instituição, não soube compreendê-lo. Corroborando esta evidência, o sujeito da pesquisa afirma que era querido por alguns professores e por outros não: [...] alguns professores gostavam de mim [...] porque eu era uma criança muito levada, alguns professores não gostavam de mim. Eu brigava com os colegas e fazia muita confusão [...].

Fica claro diante disto, que a escola buscava enquadrá-lo em um padrão comportamental. Porém, não buscava meios de compreen- 
der os motivos que estavam por trás de seu comportamento "levado", que já mostrou ter sua gênese na carência afetiva.

Ainda tendo essa postura, a escola, para R. Trindade, era um lugar atrativo: [...] Eu me sentia bem na escola, porque era um ambiente que eu estava longe do trabalho, longe da ignorância dos outros. Percebe-se também que a escola supria a carência de brincar: [...] eu gostava de Educação Física porque era onde eu jogava bola, eu gostava muito de futebol.

Porém, observa-se que a escola não reconhece a importância que tem na vida dele, e isto, se juntando à vida conturbada dentro do lar, o afasta da escola e da família, como revelam as narrativas:

[...] eu não estava estudando, eu estudei até a segunda série, eu acho que eu estava afastado da escola uns dez anos [...] eu saí de casa e fui morar na rua e comecei a me envolver com más companhias [...] já comecei a cometer pequenos delitos [...] e eu comecei a praticar outros tipos de crime e vim parar aqui dentro do IAPEN.

Seu retorno à escola acontece dentro do cárcere. É notório, por meio das narrativas, que o motivo se deu através de uma autorreflexão, depois de audiência judicial, compreende-se, então, que a motivação de estudar veio também da vontade de aprender e mudar.

Os motivos que me fizeram estudar aqui na escola foi desde a minha audiência [...] a juiza olhou a minha ficha e perguntou o que eu queria da minha vida, se eu não pensava no futuro dos meus filhos. Aí foi quando eu vim pensar o que eu estava fazendo da minha vida e resolvi lutar por uma vaga aqui [...].

Estes fatos ligam-se aos argumentos de Freire (1996), os quais falam que as barreiras que o homem enfrenta devem ser superadas para que ele cumpra com a tarefa de mudar o mundo.

Contudo, nota-se mais uma relação desumana neste retorno, agora não mais pela es- cola, mas pelo sistema prisional, como mostra o excerto a seguir: [...] foi preciso uma ordem judicial, porque o pessoal do IAPEN não queria me dar uma vaga aqui [...] (R. TRINDADE).

Embora exista amparo legal para que a população carcerária tenha acesso à educação escolar, cabe questionar: em quais medidas e circunstâncias há a aplicabilidade das leis? Nota-se, conforme as narrativas, que existem critérios impostos pela penitenciária, que selecionam quem deve ou não estudar.

[...] os educadores penitenciários fazem um levantamento de todos os reeducandos, aí quem não tem uma ficha extensa, muito suja, não tem alteração com o agente, ai ele seleciona o nome pra escola, então é um tipo de peneira [...].

Passar pela "peneira" não significa ter o direito de frequentar regularmente a escola. Arguído sobre as dificuldades encontradas para assistir as aulas, elenca: "As dificuldades de frequentar as aulas é por causa dos agentes, às vezes eles não tiram a gente pra ir para a escola, e eles ainda falam que a gente que não quer sair da cela [...]" (R. TRINDADE). Sobre isto, estudos de Viana (2015) revelam que uma parte significativa dos sujeitos operadores do sistema de execução penal não percebe o papel ressocializador que a escola tem dentro do cárcere, percebem-na apenas como um lugar onde o reeducando passa o tempo.

Nesse sentido, faz-se necessário parafrasear Haddad (2007), quando defende a flexibilização dos aspectos formais da escola, visto que eles devem dialogar com as necessidades dos alunos e realidade da escola. Nesses termos, a Escola Estadual São José deve atentar para essa dificuldade que os sujeitos-educandos vivenciam para frequentá-la regularmente, buscando alternativas para não os prejudicar, tanto na recuperação de conteúdos escolares e atividades propostas em sala de aula, quanto no registro de presenças e faltas nas cadernetas. 
Os relatos de R. Trindade revelam também que, além do poder institucional do sistema penitenciário, existe outro poder paralelo a este: o prisional, e este pode ou não interferir no aprendizado do sujeito-educando que frequenta as aulas, conforme excerto a seguir:

[...] Eu não tenho problemas dentro da cela pra estudar. Na hora que eu chego, eu pego meu material e estudo. Fico tranquilo, mas para outros que não têm bastante tempo aqui se torna dificil porque os outros pegam as folhas do caderno, mexem nos materiais, não têm respeito, mas pra mim, que já tenho muito tempo aqui, já tenho respeito e meu espaço.

Sobre isto, Vasquez (2008) revela que dentro do cárcere existem normas de convivência que ficam sob o controle ou o domínio dos presos antigos, chamados também de vozes ativas. Dessa forma, o narrador exerce o poder prisional dentro de sua cela, pois tem propriedade para isso, em virtude de estar dentro do cárcere há dezesseis anos.

Procurou-se compreender também qual a importância que o entrevistado atribui ao ensino ofertado pela escola. Obteve-se a seguinte narrativa:

A escola tem uma importância não só na minha vida como na vida de muitos também. Aqui eu vim buscar conhecimento, aprendi coisas que eu não sabia, aprendi a ler e a escrever, a ser mais disciplinado e ter respeito pelas pessoas, aprendi até mesmo a conviver com as pessoas [...]. A escola me trouxe um beneficio muito grande pra minha vida: eu resgatei o amor de muitas pessoas que não acreditavam mais em mim e hoje em dia acreditam na minha mudança.

Pelo detalhamento da narrativa, percebese que ele concebe a escola como um lugar de aquisição de conhecimento, mas também como um espaço de inclusão. Scarfó (2003 apud ONOFRE, 2011) considera que um dos objetivos da educação escolar dentro do cárcere é criar condições para que a experiência edu- cativa traga ao aluno resultados úteis, como trabalho, conhecimento, atitudes sociais e comportamentos desejáveis.

Fica evidente também, por meio das narrativas de R. Trindade, que a escola é considerada como um lugar acolhedor e tranquilo:

\section{[...] o que me faz sentir bem aqui, é porque aqui é um ambiente onde a gente pode respirar, onde a gente respira outro ar, não é um lugar sufo- cante, aqui a gente se sente bem, porque as pes- soas passam uma energia positiva, tão aqui pra ajudar a gente e a gente vê mesmo que querem ajudar a gente.}

Nesse sentido, a Escola São José mostra sua relevância como um espaço humanizador e integrador. Percebe-se que há uma interação social e afetiva entre a comunidade escolar e os sujeitos-educandos. É o lugar onde as tensões da prisão se mostram aliviadas. De acordo com Onofre (2011), o que justifica o papel ressocializador do aprisionado.

Contudo, ao falar da instituição prisional, as considerações foram contrárias às da escola: [...] a gente vive num ambiente que não é muito legal, é muito humilhante aqui dentro do IAPEN. Percebe-se também que essa humilhação narrada se estende aos familiares do narrador, quando fala dos motivos pelos quais não recebe visita no quadro de dados pessoais: "[...] eu suspendi a visita delas [...] eu estou dentro de uma instituição que é muito humilhante ai na frente", aqui ele se refere ao fato de seus familiares passarem por revistas intimas e xingamentos antes de adentrarem a cela.

Dessa forma, nessas narrativas, enfatiza-se Goffman (1974) que, ao descrever o mundo do internado, elenca as séries de rebaixamentos, degradações e humilhações pelas quais passam, e levam a sua morte civil.

As narrativas também revelaram a reflexão crítica de R. Trindade perante a escola: Ela deveria ser maior, para poder ter mais detentos 
estudando e fazer mais projetos como o Projeto da PETROBRAS - a Escola executa a última fase desse projeto que traz qualificação profissional, em diversas áreas, para os sujeitos-educandos.

A criticidade do narrador chama a atenção para a necessidade de se efetivarem políticas públicas voltadas para a Educação de Jovens e Adultos no do contexto prisional, que se mostram incipientes, pois as vagas ofertadas pela escola (375) são insignificantes em relação à demanda da penitenciária, que abriga mais de 2.716 custodiados pelo Estado.

Sobre isto, espera-se pela aprovação do Plano Estadual de Educação Para o Sistema Penitenciário do Amapá (AMAPÁ, 2017). Entre as metas propostas para os anos de 2017, 2018 e 2019 estão a ampliação da escola, o aumento do número de matrículas e a capacitação dos profissionais que atuam na escola.

\section{Análise de narrativas sobre a vida pós-cárcere}

Por fim, neste eixo, indagou-se sobre as pretensões futuras do narrador, após o cárcere, quanto à educação básica e superior, bem como seus sonhos:

[...] quando sair daqui eu já tô com a minha matrícula garantida na EJA. Eu quero fazer o ENEM e fazer um curso pra mudar a minha vida. Eu tenho que pensar nos meus filhos e na minha família. Tenho minha mãe que eu amo tanto, tenho minhas irmãs que estão me apoiando, meus amigos que acreditam na minha mudança e é por eles e por mim que hoje em dia eu luto e não vou desistir.

Instigado a falar sobre uma futura profissão, afirmou: Eu quero ser advogado, porque uma pessoa para ser advogado tem que passar por dentro de um cárcere para saber primeiramente o que é justiça, aqui é uma faculdade também (R. TRINDADE). Percebe-se que a escolha da futura profissão está relacionada com o sentimento de injustiça que, segundo Foucault (2012), o interno passa a cultivar dentro do cárcere, devido a estar exposto a sofrimentos e humilhações que a lei não previu. Nesse sentido, ser advogado seria uma maneira de fazer com que outros internos cumprissem suas penas com as garantias básicas: tratamento humano adequado e acesso aos tratamentos penitenciários, como educação, saúde e alimentação de qualidade.

Em relação ao seu sonho, afirmou: Meus sonhos é viver longe desse lugar aqui e perto da minha família, não pretendo muito não, não pretendo ser rico, só quero viver feliz e ter minha família de volta, só quero viver o resto da minha vida sossegado mesmo. Observa-se que a vida conturbada dentro do lar, quando ainda era criança e adolescente, foi o motivo que afastou R. Trindade da família e da escola, e o levou precocemente para o mundo do crime e, consequentemente, para a prisão. No entanto, este mundo mostrou-se para ele significativamente conturbado, também, e é o que hoje o motiva a resgatar os laços familiares e a tentar viver tranquilo.

\section{Considerações finais}

Em relação ao sujeito-educando da Escola Estadual São José que colaborou com este estudo, seu perfil sociocultural aponta para além das marcas identitárias gerais que caracterizam quem frequenta a EJA. Apresenta uma carência afetiva causada pela desestruturação familiar. Notou-se que o fator econômico que geralmente influencia a entrada precoce do indivíduo no mundo do crime não foi preponderante, mas, sim, os laços afetivos interrompidos pela desintegração da família, instituição considerada como o lugar propício para o desenvolvimento humano.

O perfil sociocultural desse sujeito-educando contribui para que também se apresen- 
tasse um perfil socioeducacional permeado por experiências educacionais negativas, em virtude da instituição escolar que frequentou, ainda criança e adolescente, estar preocupada em ter o modelo ideal de aluno; principalmente no que diz ao comportamento, e não com a vida social do mesmo.

Dentro do cárcere, esse sujeito-educando passa a ver a escola como uma oportunidade de mudar de vida. Ele percebe que isso é possivel, porque se sente acolhido, respeitado e valorizado por ela.

No entanto, percebe-se que dentro cárcere esse sujeito-educando convive com duas lógicas opostas: a da Escola Estadual São José, que visa, através da educação, emancipá-lo e reintegrá-lo à sociedade, e a de alguns operadores do sistema penitenciário, que ultrapassam o poder institucional, subjugando-o e impondo o descrédito em sua recuperação através da educação, impedindo-o, muitas vezes, de usufruir desse direito.

Ressalta-se, ainda, que esse sujeito-educando passa pelo processo de prisonização e convive também com o poder prisional, ou seja, o encarceramento produz seus efeitos e eles não podem ser ignorados pela escola.

Sobre a vida pós-cárcere, é claro o desejo do sujeito-educando de reconstruir a sua vida e o meio para isto é a escola e, posteriormente, a universidade, tendo como motivação a família e os amigos. Assim, ele busca, por meio da instrução escolar e acadêmica, a possibilidade de mudança e transformação de sua vida em liberdade.

Diante do que foi proposto por esse estudo, percebeu-se que é possivel que se vislumbre uma educação escolar comprometida com a humanização e a libertação do sujeito-educando, fazendo com que ele retome a autonomia perdida dentro da prisão e tenha uma futura integração social bem-sucedida.

\section{Referências}

ABREU, Almiro Alves de. Educação entre grades: um estudo sobre a educação penitenciária no Amapá. 2008. 130 f. Dissertação (Mestrado Acadêmico em Educação) - Universidade Federal de São Carlos, São Carlos, 2008.

AMAPÁ. Plano Estadual Para o Sistema Penitenciário Amapaense. Macapá: Secretaria de Educação do Estado do Amapá; Secretaria de Segurança Pública, 2017.

Resolução no 57 de dezembro de 2015.

Fixa normas para a oferta da Educação de Jovens e Adultos em ambientes de privação de liberdade. Macapá: Conselho Estadual de Educação, 2015.

ARROYO, Miguel. Educação de Jovens e Adultos. Um campo de direitos de responsabilidade pública. In: SOARES, Leôncio; GIOVANETTI, Maria Amélia; GOMES, Nilma Lima. (Orgs.). Diálogos na Educação de Jovens e Adultos. 4. ed. Belo Horizonte: Autêntica, 2011. p. $19-50$.

BARDIN, Laurence. Análise de conteúdo. Lisboa: Edições 70, 2011.

BERTAUX, Daniel. Narrativas de vida: a pesquisa e os seus métodos. Natal: EDUFRN; São Paulo: Paulus, 2010.

BRAGANÇA, Inês Ferreira de Souza; MAURÍCIO, Lúcia Velloso. Histórias de vida e práticas de formação. In: PASSEGGI, Maria da Conceição; SOUZA, Elizeu Clementino de. (Orgs.). (Auto)Biografia: formação, territórios e saberes. Natal: EDUFRN; São Paulo: Paulus, 2008. p. 253-271.

BRASIL. Lei de Execução Penal. Lei no 7.210, de 11 de julho de 1984. Disponível em: <http:/ / www.planalto. gov.br/ccivil_03/LEIS/L7210.htm>. Acesso em: 13 abr. 2018.

Pacto Internacional Sobre Direitos Econômicos, Sociais e Culturais. Decreto no 591, de 06 de julho de 1992. Disponível em: <http://www.planalto.gov.br/ccivil_03/decreto/1990-1994/d0591.htm>. Acesso em: 13 abr. 2018.

Lei de Diretrizes e Bases da Educa- 
ção Nacional. Lei no 9.394/1996. Disponivel em: <http:/ / www2.senado.leg.br/bdsf/ bitstream/handle/id/529732/lei_de_diretrizes_e_bases_1ed.pdf>. Acesso em: 13 abr. 2018.

Plano Nacional de Educação. Lei no 10.172 , de 9 de janeiro de 2001. Disponivel em: <http:// portal.mec.gov.br/arquivos/pdf/L10172.pdf>. Acesso em: 13 abr. 2018.

Resolução no 2 de maio de 2010. Diário

Oficial da União. Seção 1, p. 2, 20. Brasília, DF: 2010.

DELORY-MOMBERGER, Christine. Biografia e educação: figuras do indivíduo-projeto. Natal: EDUFRN; São Paulo: Paulus, 2008.

DIAS, Alder de Sousa. Educação de pessoas jovens, adultas e idosas: reflexões e apontamentos conceituais na perspectiva da libertação. In: BRITO, Ângela do Céu Ubaiara; DIAS, Alder de Sousa. (Orgs.). Educação e diversidade na Amazônia: práticas, reflexões e pesquisas. Curitiba: CRV, 2017. p. 243-272.

FOUCAULT, Michel. Vigiar e punir: nascimento da prisão. 40. ed. Petrópolis, RJ: Vozes, 2012.

FREIRE, Ana Maria Araújo. Analfabetismo no Brasil. 2. ed. São Paulo: Cortez, 1995.

FREIRE, Paulo. Pedagogia da autonomia. 23. ed. São Paulo: Paz e Terra, 2002.

GADOTTI, Moacir; ROMÃO, José Eustáquio. (Orgs.). Educação de jovens e adultos: teoria, prática e proposta. 12. ed. São Paulo: Cortez, 2011.

GOFFMAN, Erving. Manicômios, prisões e conventos. São Paulo: Perspectiva, 1974.

HADDAD, Sérgio. Por uma nova cultura de Educação de Jovens e Adultos: um balanço de experiência do poder local. In: REUNIÃO ANUAL DA ASSOCIAÇÃO NACIONAL DE PÓS-GRADUAÇÃO E PESQUISA EM EDUCAÇÃO, 30., 2007, Caxambú. Anais... Caxambu, MG: ANPEd, 2007. p. 1-30.

MAEYER, Marc de. Aprender e desaprender. In: UNESCO. Educando para liberdade: trajetória, debates e proposições de um projeto para a educação nas prisões brasileiras. Brasília, DF: UNESCO, 2006. p. 43-47.
OLIVEIRA, Marta Kohl de. Jovens e adultos como sujeitos de conhecimento e de aprendizagem. Revista Brasileira de Educação, v. 1, n. 12, p. 59-73, set./ out./nov./dez. 1999. Disponivel em: <http://anped. org.br/rbe/rbedigital/RBDE12/RBDE12_06_MARTA_ KOHL_DE_OLIVEIRA.pdf>. Acesso em: 13 abr. 2018.

ONOFRE, Elenice Maria Cammarosano et al. Educação escolar entre as grades. São Carlos: Edufscar, 2007.

ONOFRE, Elenice Maria Cammarosano. Educação escolar na prisão: controvérsias e caminhos de enfrentamento e superação da cilada. In: LOURENÇO, Arlindo da Silva; ONOFRE, Elenice Maria Cammarosano. (Orgs). $\mathbf{O}$ espaço da prisão e suas práticas educativas: enfoques e perspectivas contemporâneas. São Carlos: Edufscar, 2011. p. 267-285.

ORGANIZAÇÃO DAS NAÇÕES UNIDAS. Declaração Universal dos Direitos Humanos. Paris: ONU, 1948. Disponivel em: <https://www.ohchr.org/EN/UDHR/ Documents/UDHR_Translations/por.pdf>. Acesso em: 13 abr. 2018.

UNESCO. Regras mínimas para o tratamento de reclusos. Primeiro Congresso das Nações Unidas Sobre a Prevenção do Crime e Tratamento do Delinquente. UNESCO, 1955. Disponivel em: <http://pfdc. pgr.mpf.mp.br/atuacao-e-conteudos-de-apoio/ legislacao/sistema-prisional/regras_minimas.pdf>. Acesso em: 29 dez. 2016.

Educando para a liberdade: trajetórias debates e proposições de um projeto para a educação nas prisões brasileiras. Brasília, DF: UNESCO, 2006.

VASQUEZ, Eliane Leal. Sociedade cativa. Entre cultura escolar e cultura prisional: uma incursão pela ciência penitenciária. 2008. 163 f. Dissertação (Mestrado em História da Ciência) - Pontificia Universidade Católica, São Paulo, 2008.

VIANA, Selma da Silva. Educação de Jovens e Adultos em ambiente prisional: narrativas educacionais de vidas encarceradas. 2015. 88 f. Trabalho de Conclusão de Curso. (Graduação em Pedagogia) - Universidade do Estado do Amapá, Macapá, 2015.

Recebido em: 13.07.2018 Aprovado em: 26.11.2018 
Cleia Pantoja Andrade é Especialista em Educação pela UNIFAP. Professora de História da Escola Estadual São José. Licenciada em História pela UNIFAP. Pesquisadora do Grupo de Pesquisa em Educação, Trabalho e Formação Humana (GEFOR/UNIFAP). e-mail: cleiapgpantoja@gmail.com

Rodovia Juscelino Kubitschek, KM-02, Jardim Marco Zero, Macapá - AP, CEP: 68903-419.

Telefone (+55)96-3312.1765.

Alder de Sousa Dias é Professor Assistente do Curso de Licenciatura em Educação do Campo da UNIFAP. Doutorando em Educação pela UFPA. Pesquisador vinculado ao Grupo de Pesquisa Amazônia Sustentável/UNIFAP/CNPq, ao Grupo de Estudos, Pesquisas e Práticas em Educação na Amazônia Amapaense (GEPEA/UEAP/CNPq), ao Grupo de Estudos e Pesquisas em Educação, Infância e Filosofia (GEPEIF/UFPA/CNPq), sendo integrante da Rede de Pesquisa sobre Pesquisas Decoloniais na Amazônia (RPPDA).e-mail: alderdiass@yahoo.com.br

Av. Senador Lemos, 3761, Edifício Berneto, Ap. 102, Belém - PA CEP: 66120000

Cel.: (91)89242385

Eliane Leal Vasquez é Professora Adjunta do Departamento de Ciências Exatas e Tecnológicas da UNIFAP. Doutora e mestra em História da Ciência pela PUC-SP. É líder do Núcleo de Pesquisa História da Ciência e Ensino (NUPHCE). e-mail: elianevasquez@gmail.com

Rodovia Juscelino Kubitschek, Km-02, Jardim Marco Zero, Macapá - AP, CEP: 68903-419.

Telefone (+55)96-3312.1765.

Waldir Ferreira Abreu é Pesquisador do Programa de Pós-Graduação em Educação da Universidade Federal do Pará. Líder do Grupo de Pesquisa "Educação, Infância e Filosofia" e integrante da Rede de Pesquisa sobre Pesquisas Decoloniais na Amazônia (RPPDA).e-mail: awaldir@ufpa.br

Conjunto Guajará 1, WE 65, 1362. Coqueiro /Ananindeua-PA - CEP 67. 143.410

Cel.: (91)991216960 